\title{
CORRIGENDUM
}

\section{A longitudinal study of systemic inflammation and recovery of lean body mass among malnourished HIV-infected adults starting antiretroviral therapy in Tanzania and Zambia}

G PrayGod, M Blevins, S Woodd, AM Rehman, K Jeremiah, H Friis, P Kelly, J Changalucha, DC Heimburger, S Filteau and JR Koethe

European Journal of Clinical Nutrition (2016) 70, 536; doi:10.1038/ejcn.2016.1

Correction to: European Journal of Clinical Nutrition (2016) 70, 499-504; doi:10.1038/ejcn.2015.221; published online 20 January 2016

Since the publication of this article, the authors have noticed information missing in the Acknowledgements section. The beginning of the section should read:

'This study was funded by Grant No. IP.2009.33011.004 from the European and Developing Countries Clinical Trials Partnership and
CTSA Award No. UL1TR000445 from the National Center for Advancing Translational Sciences of the National Institutes of Health. Its contents are solely the responsibility of the authors and do not necessarily represent official views of the funding bodies. The funding bodies had no role in the design, conduct, interpretation or decision to publish the results of this study.'

The PDF and online versions have been amended. The authors apologise for any inconvenience caused. 